\title{
sciendo
}

DOI: $10.2478 /$ rjp-2019-0016

Rom J Psychoanal 2019, 12(2):57-69

Rom J Psychoanal

\section{THE ARCHAIC, ARCHAIC COMMUNICATION AND PSYCHIC FIGURABILITY}

Daniela Luca ${ }^{5}$

\begin{abstract}
In "Constructions in analysis" (1937), S. Freud compared the analyst's work to that of the archaeologist searching among vestiges, with the big difference that the object of our work is alive, and working with it causes fear, pain and suffering. Last year, during a visit to Pompeii and Mount Vesuvius, impressed by the strangeness of the atmosphere, by people carbonised by lava, eternal statues in a shocking atemporality among the archaic objects and traces of the place, I picked up the thread of psychoanalytic reflections on such ruins, vestiges, the layers of "ash" also present in the human psyche and their relevance in the work of the analytic cure. How to communicate the unthinkable, the unsayable, the un-representable, the barely figurable? How to transform traces of your "ancestors' ancestors' ancestors", even as passed down from Superego to Superego, or via inter-transgenerational transmissions? How to transform the formless into form?

From S. Freud to D. W. Winnicott, and W. Bion, from A. Green and J. McDougall, via D. Anzieu and R. Roussillon, the author is proposing to revisit the psychic vestiges as they are expressing during the analytic process.
\end{abstract}

Key-words: analysability, psychic archaeology, archaic communication, Ego-skin, figurability, originary

\footnotetext{
${ }^{5}$ Romanian Society of Psychoanalysis; danielaluca2@gmail.com
} 


\section{Introduction}

Last year, during a visit to Pompeii and Mount Vesuvius, impressed by the strangeness of the atmosphere, by the ground covered in a layer of dust and ash, by ruins from different periods of time and by people carbonised by lava, eternal statues in a shocking atemporality among the archaic objects and traces of the place, I picked up the thread of psychoanalytic reflections on such ruins, vestiges, the layers of "ash" also present in the human psyche and their relevance in the labour of the analytic cure. How to communicate the unthinkable, the unsayable, the un-representable, the barely figurable - I asked myself? How to transform traces of your "ancestors' ancestors' ancestors", even as passed down from Superego to Superego, or via inter-transgenerational transmissions? How to transform the formless into form? How to endure the antagonizing suffering once the lifeless "remains" you discover throughout the analytic cure are in fact experiences of the Ego, of your most intimate, earliest and therefore vulnerable Self?

In Constructions in analysis (1937), S. Freud compared the analyst's work to that of the archaeologist searching among vestiges, with the big difference that the object of our work is alive, and working with it causes fear, pain and suffering:

"His work of construction, or, if it is preferred, of reconstruction, resembles to a great extent an archeologist's excavation of some welling-place that has been destroyed and buried or of an ancient edifice. The two processes are in fact identical, except that the analyst works under better conditions and has more material at his command to assist him, since what he is dealing with is not something destroyed but something that is still alive - and perhaps for another reason as well." (p. 259)

However, more than simply comparing the two professions - analyst, archaeologist Freud sheds light on the importance of mnemic traces, of the vestiges of psychic life (living / non-living archaic objects, archaic defence mechanisms, remains of primal representations, archaic scenes etc.) that construct our being and that, once we explore in our search for them, either return by themselves with volcanic force, or, other times, urge the appearance of pain, anguish, agony, internal struggles, symptoms, maladies etc.:

"Here we are regularly met by a situation which with the archaeological object occurs only in such rare circumstances as those of Pompeii or of the tomb of Tut'ankhamun. All of the essentials are preserved; even things that seem completely forgotten are present somehow and 
somewhere, and have merely been buried and made inaccessible to the subject. Indeed, it may, as we know, be doubted whether any psychical structure can really be the victim of total destruction. It depends only upon analytic technique whether we shall succeed in bringing what is concealed completely to light. There are only two other facts that weigh against the extraordinary advantage which is thus enjoyed by the work of analysis: namely, that psychical objects are incomparably more complicated than the excavator's material ones and that we have insufficient knowledge of what we may expect to find, since their finer structure contains so much that is still mysterious. But our comparison between the two forms of work can go no further than this; for the main difference between them lies in the fact that for the archaeologist the reconstruction is the aim and end of his endeavours while for analysis the construction is only a preliminary labour." (p. 260)

\section{The Archaic, from the unfigurable and uncommunicable to figurability and meaning}

But what is this mysterious archaic from beyond time, from barely visible and tangible psychic spaces, what disturbs us, recalls us down the line of our own history and that of previous generations, beckons us while we can barely speak its name. Even if we could say it, it can often barely represent itself in order to be thought of and uttered.

We could consider that the archaic is a defensive construction against a shapeless primordial time and against the impression of a void, felt by the subject who emerges from the initial chaos. Only through regression towards the atemporal unconscious may we encounter this archaic foundation at the base of the subject's construction. It is at the same time a form of primitive content impervious to historicisation, which we can encounter on a social level as well. We can discern and describe the archaic, as A. Green specifies in his article, "Retroactively, the archaic", only in the après-coup, and discover those pre-existing structures, which formed in different psychic times and eventually led to the current one: "If it were true that the unconscious is marked by the inscription of the most primitive psychic mechanism belonging to the beginnings of psychic life and that it does not know time, then it is reasonable to think that the structures which were built upon the original inscriptions weren't content merely to superimpose themselves over them. They were not constituted on the archaic, but against it. They tried to modify its functioning by linking, symbolisation, differentiation etc. In short, we must read the archaic retroactively, it is the only way to speak of it; we will guess or deduce it a posteriori, behind or under the ramparts built against its threatening power." (p. 235) 
Since the beginning of life, the subject is confronted with a fundamental experience of suffering and distress, with an "aesthetic conflict" (D. Meltzer, 2008). We can figure this primordial state, taking into account that the child within the womb is propelled into a world radically different from the previous one, which had contained it and protected it during those nine months, before it enters the external world. In the precedent universe, we can assume it found a nearly perfect and complete satisfaction of its needs for development. In this confrontation with the exterior world, the child will feel itself in a state of abandonment, both physiologically as well as psychologically, tied to the effects of the fundamental deficiency, strengthened by the confrontation with the unknown and the formless. This fundamental deficiency is due to a difference in containing and answering vital needs, which leads to states of maximal uncertainty. This state is even more important as the baby is not capable of selfsatisfying its basic needs in order to stay alive. As Guyotat points out, when talking about the life-death coincidence, during these primordial moments of psychic life, the experience of death could be felt in this inaugural space-time at the beginning of life.

In most cases, this agonising archaic state of uncertainty, of fundamental distrust, would be partially covered by the care provided by the environment, especially maternal care, essential for the survival of the child. During this primordial period, far from any possibility for expression through internal/external language, the baby needs this object, this Other, who will satisfy the first vital needs, feeding, the nyctohemeral rhythm and body care playing an essential part. Therefore, there is an initial call to the other, which allows the apparition of the state of danger associated with the necessary satisfaction of needs. The reliable adaptation of the maternal environment to the vital needs of the baby, as D. Winnicott specifies in various articles of his, is absolutely essential for the integration and maturational processes of the baby's Ego, for a construction of the Self and for a healthy development.

Primordial helplessness is a first fundamental experience, a basis, a nucleus of organisation and structure, which will surely have to endure primal repression. This state of primitive, archaic helplessness can return as such or can come back more-or-less in a confused manner, when, in his or her ulterior life, the subject will have to go through experiences that reactivate the conditions for primal abandonment. Such a distress is the mark of an experience of primitive terror, when facing a vital deficiency, which the child protects itself from by retreating and/or by relying on the support of the Other. This support is facilitated by the presence of a mother or an efficient maternal substitute, a good carer. However, the child may 
continue to try and ignore, by negation, omnipotence and magical thinking, this alterity, and figure / imagine a capacity for narcissistic auto-satisfaction, typical of original narcissism.

The concomitant representation desire and activity will engraft on these experiences linked to the satisfaction of basic needs, thus allowing the primordial state of fundamental deficiency to be overcome, and of the need for confrontation with the helplessness-causing formlessness. The desire will manifest either as an attempt to find this meeting with the Other again, either through its omnipotent denial, even under the guise of a "desire for a non-desire", a translation of the death drive. The experience of satisfaction and pleasure involves, alongside the desiring activity, the act of representation. Since birth, the subject holds a propensity to envision and then to represent the object of need, the Other. This original representation involves a capacity to hallucinate the missing object of need. In fact, the baby can live the immediate un-satisfaction of its needs only partially through the hallucinatory capacity to represent the absent object. (my underlining)

We observe that representation relies both on the perception of external reality and on the hallucinatory construction of fantasy. The experience of need that concomitantly structures desire is organised by "taking in" introjection/internalisation and "throwing out", evacuation/projection, respectively taking within/internalising and keeping that something which is good or the source of pleasure, and throwing out/projecting that which is perceived as bad or as a source of discontent. The categories of good/bad as well as that of Self/other Self, are intrinsically linked to the experiences of pleasure and displeasure/pain, to the extent that these are components and organisers of desire.

Piera Aulagnier showed the paradigm of the archaic's appearance by postulating, in the act of representation, the original pictogram of acceptance / rejection, starting from the primal processes of fantasy and the secondary processes of the idea/thought. For Sophie de MijollaMellor ("De l'informe à l'archaïque", 2005): "The archaic can be defined as the embodied form of surviving, the repeated, updated form of a fossilised history. These purified forms, condensed in images or words, are destined to repeat themselves identically in oneiric experiences or in the experience of the unsettling strangeness, for example, as well as to be elaborated into a myth". (p.18)

The primal self-image would be constituted on the basis of an unravelling suffering, converted into an experience of pleasure. It would tend to exclude any trace of the Other/of the Object which seeks to represent, thus following the path of the paranoiac potential. Moreover, 
the Ego, as representative of the traces of life, could also be the target of attacks aiming for its annihilation/death, as is the case in the melancholic structure. On the other hand, while masochism develops on the basis of sexual drives and death drives, we can observe the frailty of this intersection, to the point that the death drive, through its annihilating effects, proves to act rapidly so that psychic functioning can reach a point of inertia that comes close to the lethal state of the Ego (A. Green - de-subjectualisation) or of the object (A. Green - deobjectualisation), depending on the predominance of the masochist impact or of its sadistic counter-investment. In short, since its origin, the subject is confronted with the structure of an archaic system directed/dominated by masochism and sadism (primal orality and anality, see R. Roussillon), the purpose of which is the triumph of solipsism over any alterity; this solipsistic vision flirts dangerously with the destruction of the Self and of the other.

This archaic foundation of the psyche's architecture, which induces a fundamental "egocentrism", constitutes a permanent point of attraction, which the primal or secondary subject will always have the tendency to reach for in search of refuge. However, as we have seen, since the beginning the subject required an Other to survive. Therefore, ever since the "archaic", the subject is caught in the register of alterity as well, and, moreover, the subject originates from an Other that existed and always exists outside of the subject. The psychic subject is therefore composed of two antagonistic tendencies that remain in a more-or-less open dialogue. Between the solipsist tendency to retire and the openness to alterity, the historic subject will find itself in varied situations, and will have to continuously make choices. Nevertheless, for the psychic subject to best follow its path within its own temporality and historicity, it will be necessary to refer to a third position, which would allow it to be free of any confusion with the maternal psychism. From the start, this reference implies the paternal function in its primordial setting, the only one which truly opens up to the register of alterity, tridimensionality and secondary symbolisations, including identifications.

Piera Aulagnier (1975) was the one who conceptualised the symbolic identification depending on the concept of space: "The space in which the "I" [Je] must come about, which is also the only space in which it can come about, shows that its organisation is placed under the aegis of a series of linguistic signs - those proper to the affect and those proper to the system of kinship - which, naming a thing or an element, define the relation present between the object being named and that which appropriates and states that naming”. (p. 169)

Symbolic identification is the organiser of the identity structure for any psychic subject. Its structure relies on two fundamental interdictions: the interdiction of incest and the 
interdiction of murder. As a result, its function is to organise the identification positions by forbidding certain drive acting-outs, incompatible with cultural and social norms, the breaking of which would involve the risk of identity loss. Symbolic identification is one of the elements of primal identification. It is an identified, and therefore identifiable, set that emerges from a transcendent register transmitted by the register of society; narcissistic identification constituted on the basis of the archaic is the other component of primal identification. This "project for identification" appears as a problematic of the internal tension of the psychic subject, a tension between the symbolic identification with the Other/the Object and narcissistic identification with the Self. Therefore, because of the potential utilization of every pole of the identification project, but also because of the tension between the two poles, the search for identification endures in time, at least up until the moment of psychic death, which does not necessarily correspond to biological death. The interactive tension between a conservation tendency of the Object, depending on the manner of narcissistic identification, and a tendency for sublimating idealization, on the model of symbolic identification, will continuously accompany the psychic subject throughout his/her life and death experiences.

\section{The Archaic in the analytic cure: two clinical illustrations}

\section{Case 1. "I think the Pompeii within me is different from the Pompeii within others..."}

Mrs M, a 35 year old patient with four weekly sessions of therapy due to a psychic breakdown, which she perceived as a danger of going mad, experiencing intense depressive, agitated and anguished states, with the sense of loss of bearings/landmarks, lack of selfknowledge, tornados of ideas and memories that keep her tense and prolonged insomnias, making a daily effort to work and lead her daily existence without others realising the nightmare she's going through. She often refers to the Pompeii within her and to certain moments when her internal "Vesuvius" scorched her after its eruptions.

The first experience of this kind she remembers dates back to when she was 2-3 years old and her "mother disappeared" for a few weeks, without the girl being able to understand why, not being told where she was and why it was happening. Upon her mother's return, M. felt even stranger, because her mother had acted completely different towards her, lacking the warmth and affection she exhibited before her "disappearance", instead manifesting in explosions of impulsiveness, anger, arguments, punishments and beatings that lasted around until the patient turned 19. She felt the second "scorching" experience one evening when she was 10 , and her parents announced their divorce to the children, suddenly, implacably, coldly, 
detachedly, without taking into consideration the impact it had on them. She remembers feeling as if frozen, followed by a state of burning rage, then agitated fright, and the only thought that went through her mind then was if she would become homeless. The third experience which consumed her to the bone, just as Pompeii was consumed by the flames, as she described, was a separation from a significant other/female lover, a homoerotic choice accepted by both partners, completely by her and partially by the other, which led to oscillations between icyviolence and fiery-violence. The brutal rupture, felt like a blow to the head, it broke her down. She sought therapy after this experience, in which her own violent rage, like unstoppable lava, made her fear losing her mind entirely.

The first two years of analysis took place on an archaic psychic stage, in which crushing, threatening psychic elements and objects, catastrophic and terrifying fantasmatic scenarios, primitive affects, cruelties, emotional violence, avalanches of excessive memories, admonitions directed towards everyone in her life, from childhood to present day, a furious hatred towards Man, mankind, humanity - the extension of a schizoid-paranoid primary hatred towards the primary object, the continuous impact of the sadistic drive, self-destructive, the tendency to completely barricade behind insurmountable defences (my "great wall of China"), avoiding all sorts of fantasies, free-associations, massive tendencies towards justification and intellectualisation, all these suspended or even deadlocked the analytic working-through, coworking, co-creating and, on the flux of an intense homoerotic and idealising erotic transfer, any approach of painful experiences or unprocessed mourning and violent ruptures was difficult.

All these could change a minima once the analyst, as her mother had once done, "disappeared" from the transference-countertransference lava, in some sessions losing emotional contact with the patient and thus cutting out a personal space from which to view what was occurring between herself and the patient in a different manner. Returning to a rather male-paternal position, through the tertiary function of the setting, especially of time, of the elaboration of rules' meanings in relation to the internal archaeology of the patient, led to Mrs M's emergence from the burning magma of erotised and erotising fusion, also violentdestructive, with the transferred maternal object, and, through insights into her relationship with the father and understanding, accepting and integrating decomposed images of the latter, she managed to gain access to the tertiary dimension and the capacity to think the "scorching" experiences. The most difficult task however was working on a condensed, psychic and real image, the Pompeii statue of the mother carrying her child, which to her did not signify dying 
together so much as an eternity together, beyond death. For this work to begin, another momentary therapeutic failure was "necessary", namely the "disappearance" of the analyst, this time relating to a health concern that required the cancellation of some sessions. This "disappearance"/absence of the analyst, received by the patient with apparent acceptance, conformism and understanding, did however trigger rebellious and attack movements directed towards herself and the internal maternal object, which had to be noticed by the analyst and directed to the setting of the analytic relationship: getting hours mixed-up, tardiness, forgetting the amounts paid (sometimes underpaying, sometimes overpaying), an often sarcastic tone, reckless endangerment that demanded police intervention and anger towards the authorities etc.

These archaic tectonic movements, with their lava of destructive, deadly contents, attenuated throughout the analysis, as Mrs M managed to internalise a safe enough, vital, trustworthy relationship with an object other than and different from the maternal / paternal / fraternal object or the substitute objects she "had and lost for an entire lifetime". "The Pompeii within me is different from the Pompeii within others...", the patient confessed towards the analysis' end, when the differentiation, absence-presence, dyad and triad work helped achieve the capacity to define one's self separately from the other objects, and also to the ability to better distinguish their characteristics.

\section{Case 2. "Do you know what it's like to continuously feel a huge boulder hanging above your head, ready to crush you?"}

Mr P., 28 years old, requested a classical analysis, as he made clear in the first minutes of our first session, three times a week, emphasizing since the beginning that he had an exact amount of money for the analysis and that, when it was spent, he will have to end the cure. He mentioned that, should we begin analysis, I would be his $8^{\text {th }}$ psychoanalyst in a row he started ten years ago. Some were analysts, others not, he had attended several sessions with some, and months and years with others. He insisted on pointing out he knew all rules perfectly and that there is no need to waste time repeating them with me, he had heard them enough, read them, saying he had read more psychoanalysis than some psychoanalysts. That he could at any moment tear down certain aberrations in psychoanalysis books and articles, which he had done, from Freud to the present day, especially since it helped him maintain his own opinions, and that he does not let himself easily influenced by others. He continued with how he would lie down on the couch, not because Freud said so, but because he hated looking at a human being 
for so long. He knows the rule of confidentiality very well, so he doesn't care if I ever write an article or book about him.

I mystifyingly observed this stony, tough, arid, defying, arrogant, lifeless, non-human speech, asking myself how much psychic energy this man consumed throughout his lifetime to become - or try to become - a block of stone, to protect himself from any possible emotional wave from within to the outside. It was not the way he set the analytic situation, tracing the rules and dislodging the therapist/analyst, that I found intriguing, as I'd encountered it in two analytic experiences with two patients that had gone through psychoanalytical psychotherapy, but the movement of annihilating life, the Other, both interior and exterior, and implicitly of his own vitality.

Mr P described his parents like a scene from a Nazi death camp, outright calling them "fascists", then elaborating on, paradoxically, his fascination with Hitler. Since he was a young child he perceived them as brutes, soulless, sadistic, insane, and, anyway, so were his grandparents and siblings. He triumphantly and sarcastically stated that he managed to get rid of them only in his teens, violently protesting until he got his own room in the family's sumptuous villa, where he did not allow anything living: no trace of human, animal or plant. In high-school he had fallen for a girl, his great mistake according to him, who he'd written poetry for, and her and "her moronic friends" laughed at him. Since then, he'd needed no other love, he said he hated women, "in fact no, I'd exterminate them, they have no purpose in the world, not that men do".

The sessions always went in a rigid-ritualistic way, like a prison-citadel, from which the patient launched a challenge or question my way from time to time, and if I managed to intervene in any way he immediately parried me with lines such as "This is stupid!", "Nonsense, it’s illogical!", "Psychoanalytic foolishness!". He always arrived on time, not a second sooner or later, like a Swiss watch. After precisely 45 minutes, his eyes on the clock, he stood up just as rigidly, turned towards me in a military fashion, stared straight, left the money on the table and left stiffly.

Helplessness, futility, uselessness, meaningless, useless - of varying intensities and amplitudes - that's what I felt every minute of every session. Among those where a clotted and knotted / locked-up speech about his family, events from childhood and adolescence, with some scatterings from the present, was predominant, there were also sessions where he came prepared with 3-4 dreams, which he evacuated in great detail, accompanied by "self-interpretations", 
filling up the space of the session entirely. And, although it seemed that, as an analyst and as a human being, I have no purpose in the clinic's space, I was reduced to an inanimate object, nonhuman, not alive, and that it was necessary to remain so under the patient's control, the patient who came with tenacity, punctuality, like a soldier, never missing a session. I did not have to be as a living being, but I still had to exist, present there for him, as was tolerable to him. Only like that. This prison atmosphere, like a jail cell where I was both captive and witness, lasted in the same form for the first 4-5 months, but was interrupted by a question I asked, following a session during which the patient proudly recounted how he'd humiliated some therapists and how he tore down their phrases or written texts. Finally, involuntarily, Mr P left me an opening through which I could have a live exchange, so I took the risk - the risk of provoking a sadistic, annihilating and ample attack and even the end of analysis - and asked:

- "And if you managed to humiliate the other therapists, analysts, to tear down their verbal and written discourses, how did you end up asking me for analysis?"

He didn't fight the question, on the contrary, he seemed prepared to answer, and said:

- "I still wanted to complete an analysis, I searched again and found two of your articles on an institution's website... And, comparing them to other articles, written by others, yours seemed to have something human, alive."

- "What do you mean by human, alive?", I question further, almost whispered and unexpectedly warm, even for me, it being one of the rare authentic dialogues possible in the first three years of analysis (there were two cases, the second occurring later, almost one year apart).

- "What a question!" he replied angrily, offended, irritated. And yet, he carried on: "Do you know what it's like to always feel, continuously, every second, a huge boulder hanging above your head, at risk of falling and crushing you at any moment?!"

- "Like in that Magritte painting, "The Castle of the Pyrenees", that you spoke of in one of our sessions?" I made the reference knowing it was yet another risk, because he felt threatened by the idea that I could have a good memory, that I could understand how he is, how he feels, what is happening to him and how he suffers beyond all the sadism and defences he manifested.

- 'Exactly so! But you do not know, I don't think you've ever felt what it's like to experience this continuously."

- "You feel this continuously here too."

- "I'd rather not answer this." 
On my part, this time it was a statement, a certitude uttered as such, not a question. However, the non-answer / refusal of the patient was, as it often occurred during our two analysis instalments together, more alive and true than any verbal form of discourse.

What psychic scene are we referring to when we say that a patient transfers primal, archaic elements onto the analyst? The enigmatic archaic, the barely-touched, barely represented, barely imagined and almost unthinkable, unnoticed or incomprehensible. The archaic that is, as Bernard This wrote, at the beginning of all beginnings, at the origin of things, the principle, the point of departure for all resources, that, once given life, guide us, offer us the reference marks, the matrix of existence. But at the beginning of what, an analyst may ask, when he or she feels the resonance of the patient's suffering reaching a psychic limit difficult to discern. At the beginning of birth, of the foetal life, of conception, before conception, from the maternal and paternal unconscious, its filiation, its tree of life? What is the limit reached by archaic time and space, the original affective and fantasmatic matrix in which Psyché was born, how do we identify in intimate, almost inaudible, unconscious - unconscious communication, what is transferred from the patient and what emanates in countertransference from the analyst towards the patient? (clinical vignette, confidential)

Joyce McDougall in "Countertransference and primitive communication" (in Plea for a Measure of Abnormality) asked what happens in the case of patients who are severely affected by early infantile trauma from the start of their lives, precisely those events which are produced before language is acquired, when the child communicates using signs. She adds that any "communication" is out of the question as long as there is no Other to receive these signs, to decipher them and give them meaning. This is why the first reality and first relation of any child is the maternal unconscious. The traces of this first relation/communication is not however stored in the preconscious, which means they are not accessible to be remembered. As they never occurred in the symbolic chain, these pre-verbal traces cannot find expression through repressed fantasies and therefore cannot return in order to fulfil a purpose for a neurotic symptom.

The traumatic phenomena of the infant are linked to the primal repressions and splitting. During this period of life, psychic suffering is not perceived as different from physical suffering. The metaphoric discourse of psychotic patients, as Joyce McDougall informs us, just like psychosomatic manifestations, offer us numerous examples. We need to understand the mother-child primal communication in order to identify those archaic contents within the 
analytical relationship, inherent for the analyst-analysand communication, in the form of symbiotic, borderline or paradoxical transference-countertransference. For these patients, "any connection to an emotion, situation or representation that risks bringing back to life the original catastrophe is immediately broken, eliminated from the psyche, in a way that the subject suffers a real disturbance of verbal thinking. The subject will not know to leave the necessary space to capture these unconscious thoughts. Once the sketch of their affect or representation is banished outside, the patient often adopts without transition behaviours that mask the void left behind by rejection and which, undoubtedly, also serve as a way to discharge. In this respect, speaking can be a behaviour". (McDougall, 1992)

In the case of non-neurotic patients, speaking can be seen as an action onto the other/the analyst, to reach the one listening, act upon him/her, invade him/her, which often renders free association inoperable. To them, speaking is a way to discharge / evacuate painful tensions by the intercession of a language that has the purpose, above all else, to share what is, at the time, unutterable, unsayable: the word leans more towards sharing the experience, emotion, affect, rather than communicating ideas. It is a demand to be heard, and not as much to be listened to.

\section{REFERENCES}

AULAGNIER, P. (1975). Violence de l'interprétation. Paris, PUF, 1975.

FREUD, S. (1937). Construction in analysis, in Freud S., and Strachey J. (trans), The standard edition of the complete work of Sigmund Freud. London, Hogarth Press and the Institute of Psycho-Analysis, 1964, pp. 255-270.

GREEN, A. (1990). “Après-coup, l'archaïque”, in La folie privée. Paris, Gallimard, 1990, pp. 225-253.

McDOUGALL, J. (1992). Countertransference and primitive communication, in Plea for a measure of abnormality. N.Y, Brunner Mazel Publishers, 1992, pp. 247-298.

MELTZER, D., WILLIAMS, M. H. (2008). The apprehension of beauty: The role of the aesthetic conflict in development, art and violence. London, Karnac.

DE MIJOLLA-MELLOR, S. (2005). De l'informe à l'archaïque, Recherches en psychanalyse, 3(1): 7-19. Paris, Ed. Association Recherches en psychanalyse 